\title{
Nietzsche y Brahms
}

\author{
JOAN B. LLINARES
}

A quien se interese por la música en la persona y la obra de Nietzsche (1844-1900) le ha de resultar altamente significativo que el filósofo también mantuviera determinada relación puntual y entrecortada con la música y la persona de quien fue, junto con la revolucionaria y poderosísima personalidad de Richard Wagner (18131883), uno de los compositores más relevantes de su tiempo, uno de los verdaderamente grandes en la historia del arte de los sonidos. Como es bien sabido, Wagner llegó a ser, sin lugar a dudas, la relación decisiva en la vida y la obra de Nietzsche: su biografía, sus escritos, sus fragmentos póstumos y su epistolario lo demuestran a todas luces 1 . Si nos guiáramos por ella, esa otra relación, la que tuvo con Johannes Brahms (1833-1897), es, en efecto, incomparablemente menor y mucho más reducida. No obstante, también alcanzó sus honduras y generó algunos sorprendentes frutos bien explícitos que aquí deseamos recordar, traducir y comentar en una primera aproximación, dadas nuestras limitaciones musicológicas y las pertinentes dimensiones de un artículo. Si este texto sirve para que se reconozca y se prosiga esta poco frecuentada pista de la que queremos brindar un mapa de

1 Cf. Nietzsche und Wagner. Stationen einer epochalen Begegnung, ed. D. Borchmeyer y J. Salaquarda, Insel, 2 vols., Frankfurt a. Main y Leipzig, 1994, 1418 pp. 
conjunto, el trabajo habrá logrado sus objetivos: demasiado sabemos que buenos lectores de Nietzsche y, en especial, de sus libros sobre Wagner, ni siquiera reparan en esta veta en absoluto escondida, aunque, a juzgar por los comentarios, casi siempre resulta incomprensiblemente postergada y hasta proscrita, como si no existiera. Intentaremos paliar, por lo tanto, este inmerecido olvido.

La perspectiva de la que partimos - Nietzsche y Brahms- es claramente parcial, nos proponemos reconstruir los pormenores de esa relación desde el punto de vista del filósofo. Con ello indicamos que queda abierto el flanco correlativo, esto es, su estudio desde el músico, enfoque éste - Brahms y Nietzsche- que también tiene valiosas aportaciones que ofrecer, como ha demostrado, p. ej., Joachim Reiber, colaborador de la vienesa y brahmsiana Gesellschaft der Musikfreunde. Gracias a sus investigaciones sabemos que el compositor leyó al filósofo, y no de forma esporádica: Mas allá del bien y del mal, La genealogía de la moral, el Himno a la vida y un tomo de las Obras completas, el VIII, editado en 1895, que contiene El caso Wagner, Crepuísculo de los ídolos, Nietzsche contra Wagner, El Anticristo y Poemas. Este volumen y el de la primera edición de La genealogía de la moral se encuentran en su biblioteca: tanto los subrayados como los diversos signos plásticos de apasionada lectura que esos ejemplares conservan, atribuibles al gran músico, permiten deducciones esclarecedoras ${ }^{2}$. Otros testimonios epistolares o indirectos de su aleccionadora relación con Nietzsche, que parece ser que surgió motivada en gran medida por el interés que había demostrado por la obra del filósofo uno de los buenos amigos del compositor, el agudo crítico literario suizo Josef Viktor Widmann (1842-1911) —autor de importantes reseñas de algunos libros de la madurez del pensador-, merecen detenido análisis. Al hilo de nuestra exposición, intentaremos que aparezcan con cierta suficiencia, pero sin pretensiones de exhaustividad ni la matizada reconstrucción que requieren, como hemos dicho. Tampoco nos detendremos en el estudio de los artículos que Widmann dedicó a Nietzsche ni en el de su epistolario en estos dos frentes, el que sostuvo con el filósofo y el que cruzó con su amigo Brahms, notables documentos que también con-

2 Cf. J. Reiber, «"Auch das Gegenteil kann wahr sein”. Johannes Brajms, Josef Viktor Widmann und Friedrich Nietzsche», en G. Pöltner y H. Vetter, Nietzsche und die Musik, Peter Lang, Frankfurt a. Main, 1997, pp. 57-79. 
servan innegable interés histórico y teórico y que enriquecen las necesarias consideraciones para abordar con fundamentos suficientes las relaciones entre el filósofo y el gran músico de Hamburgo y las mediaciones que las configuraron ${ }^{3}$.

I. UN EPISODIO PARADIGMÁTICO: LA CANCIÓN TRIUNFAL DE BRAHMS Y LAS CRECIENTES TENSIONES CON W AGNER

Es imposible iniciar la reconstrucción de los testimonios de Nietzsche con respecto a Brahms sin reconocer que se insertan en el seno de los complejísimos, apasionados y omnipresentes lazos que unieron al filósofo con su excepcional amigo de juventud, Richard Wagner. Así sucede, en efecto, como demuestra este primer episodio, tan sugerente y premonitorio.

Con motivo de la victoria militar alemana en la contienda con Francia en la guerra de 1870-1871, tanto Wagner como Brahms compusieron música triunfal, a saber, la Kaiser-Marsch (Marcha del Emperador, dedicada a Guillermo I), acabada el 15 de marzo de 1871, que tiene el $\mathrm{n}^{\circ} 104$ en la WWV, y el oratorio Triumphlied (Canción triunfah) para barítono solista, coro de 8 voces y orquesta (órgano ad libitum), de 1872 (compuesto en 1870-71), op.55, con textos del capítulo 19 del Apocalipsis del Nuevo Testamento —obra que, como ha explicado C. P. Janz, sigue el modelo del Te Deum de Detting de Händel一, respectivamente. Son obras de difícil audición en nuestros días, incluso a través de grabaciones discográficas o en $\mathrm{CD}$, y esas raras versiones están interpretadas, además, por directores y orquestas poco reconocidos; según la opinión de muchos especialistas, no pertenecen a lo más significativo de la producción de ambos músicos, a pesar de que la composición de Brahms parece ser "una obra valiosa", al menos para

3 Cf. Ibid. para el epistolario de Widmann con Brahms; los artículos a los que nos referimos son: J. V. Widmann, «Nietzsche's gefährliches Buch», Der Bund, Berna, 16-17 de septiembre de 1888, $\mathrm{n}^{\circ} 256 \mathrm{y} \mathrm{n}^{\circ} 257$. (Se encuentra reproducido en C. P. Janz, Friedrich Nietzsche 4. Los años de bundimiento 1889/1900, tr. J. Muñoz e I. Reguera, Alianza, Madrid, 1985, 201206); J. V. Widmann, «Nietzsches Abfall von Wagner», Der Bund, Berna, 20-21 de noviembre de $1888, n^{\circ} 321$ y n ${ }^{\circ} 322$. (También puede consultarse en C. P. Janz, op. cit 220-228); y J. V. Widmann, «Brahms und Nietzsche», Die Zukunft, 19, 1897, en polémica con P. Gast, «Nietzsche und Brahms», Die Zukunft, 19, 1897, 266-269. 
el citado musicólogo C. P. Janz $z^{4}$. Son, ciertamente, obras ocasionales o de compromiso, frutos de aquellas muy peculiares y viscerales circunstancias políticas, en especial la marcha de Wagner, aunque en el caso de Brahms el oratorio respondiese también a sus profundas convicciones patrióticas, indiscutiblemente inclinadas a favor del Imperio alemán, del artífice de ese Segundo Reich, el canciller Bismarck, y de la primacía de la dinastía prusiana, que, como es bien sabido, ostentaba la capitalidad y la corona de dicho Imperio.

El orfeón de Basilea, con motivo del 50 aniversario de su existencia, la eligió para su tercera celebración festiva el día 9 de junio de 1874 , organizando un gran concierto con más de trescientos participantes, evento que tuvo lugar en la catedral de la ciudad suiza, bajo la dirección del propio compositor, con asistencia del por entonces catedrático de filología clásica de su Universidad, el profesor y melómano Friedrich Nietzsche. A éste le impresionó la obra y su audición le obligó a plantearse problemas de estética musical, como sabemos por la carta a su amigo Erwin Rohde del 14 de junio de ese año:

«Últimamente estuvo aquí tu compatriota Brahms; oí muchas cosas suyas, sobre todo su Canción triunfal, que dirigió él mismo. Fue para mí una de las más difíciles pruebas estéticas de conciencia el entenderme con Brahms [Es war mir eine der schwersten aesthetischen Gewissens-Proben, mich mit Brahms auseinanderzusetzen]; ahora tengo una opinioncilla sobre ese hombre. Pero todavía muy tímida»5.

Sobre la positiva impresión que le causó la música de Brahms —además de la obra citada, ¿qué otras 'muchas cosas' escucharía del compositor, seguramente en versiones para piano, ya que en el programa del concierto de Basilea no figuraba ninguna otra composición suya? ¿Ein deutsches Requiem, op. 45, de 1868, que ya por entonces tuvo mucho éxito? ¿Schicksalslied, op. 54, de 1871, que algunos han relacionado, junto con la Canción triunfal, con la versión para cuatro manos de esa gran fantasía musical del Nietzsche compositor, caligrafiada en abril de 1874, y que primero se denominaba Hymnus auf die Freundschaft (Himno a la amistad)?-, sobre su atenta recep-

4 Cf. C. P. Janz, Friedrich Nietzsche 2. Los diez años de Basilea 1869/1879, tr. J. Muñoz e I. Reguera, Alianza, Madrid, 1981, p. 245.

5 F. Nietzsche, Sämtliche Briefe, Kritische Studienausgabe, ed. G. Colli y M. Montinari, München-Berlin/Nueva York, DTV-de Gruyter, 1986, tomo 4, 236 (citaremos KSB 4, 236). 
tividad tenemos, en efecto, varios datos, p. ej., que cuando el 12 de julio se volvió a interpretar en el Festival de Zürich la Canción triunfal, Nietzsche viajó allí con su amigo H. Romundt para escucharla, aunque esta vez la dirigía Friedrich Hegar, un músico apreciado por él, a quién le había enviado su composición Meditación de Manfredo, inteligentemente comentada por aquél cuando se la devolvió. Por cierto, en la carta de comienzos de abril de ese año, 1874, en la que Nietzsche le reclamaba la devolución del manuscrito de esa obra musical, ya se lee - junto con el inevitable recordatorio de una nueva representación del Tristán en Munich e inmediatamente a continuación-, el explícito deseo del filósofo por asistir al anunciado Festival de Zürich, expresado en estas significativas palabras: «me alegro especialmente de poder escuchar, ipor fin!, la Canción triunfal. [ich freue mich besonders darauf, das Triumphlied endlich! zu hören]» 6 . El segundo dato es que se procuró la versión para piano de esa obra de Brahms, la estudió con detenimiento y la llevó consigo en su viaje a Bayreuth, en poco propicias condiciones de salud, los días 4 al 15 de agosto de ese verano.

Por lo que relatan diferentes informes ${ }^{7}$, parece ser que durante el segundo día de su estancia, el 6 de agosto, por la tarde, después de haber tocado Wagner al piano la escena de las hijas del Rin del final del Crepuísculo de los dioses, Nietzsche trató insistentemente, con la citada partitura para piano de la Canción triunfalen sus manos, de que el compositor reconociera la valía de la música de Brahms, pero el intento salió frustrado, pues Wagner reaccionó con risas y carcajadas, le pareció ridículo que se hubiera puesto música a la palabra Gerechtigkeit (justicia). El día 7 se guardó silencio sobre el asunto, si bien el sábado día 8 se interpretó al piano la partitura que Nietzsche había traído y elogiado, pero que los Wagner encontraron deplorable, sobre todo el compositor, que la criticó duramente - Händel, Mendelssohn y Schumann, pero envueltos en una piel de cuero-, muy enfadado por no poder encontrar música en esa pieza. Alabó, por el contrario, a Liszt como genui-

6 KSB 4, 213.

7 Cf. los apuntes de las citadas fechas del Diario de Cosima Wagner, que pueden consultarse, p. ej., en la gran obra de Borchmeyer y Salaquarda que citamos en la nota 1. También aparecen detallados en la biografía de W. Ross, Der ängstliche Adler, Deutsche VerlagsAnstalt, Stuttgart, 1980, 309-405. (Hay trad. castellana.) 
no músico capaz de expresar la religión cristiana, y acabó tocando su propia Marcha del Emperador como punto final definitivo sobre la cuestión. Fue menester que Cosima interviniera con todos sus encantos y saberes diplomáticos para que no se agravara la grieta que esa reacción abrió en las relaciones entre el filólogo y el músico, recíprocamente desencantados y hondamente desilusionados por su desencuentro estético.

Proseguía así una secreta senda de alejamiento y distancias, en especial por parte de Nietzsche: la actitud de Wagner le desmoronó la 'grandeza' que tan generosamente le había otorgado desde la tarde en que le conoció, pues pasó a considerar que la personalidad del músico, como si fuera la de una especie de déspota celoso, no tenía suficiente fuerza ni bastante confianza en sí mismo, siendo incapaz por ello de reconocer y apreciar la valía de otros artistas. En una palabra, comenzó a perderle el profundo respeto que le tenía, y quizá perdure ese mal recuerdo en las hirientes bromas que años después escribirá sobre esa Marcha del Emperador que en absoluto supera en calidad a la denostada composición de Brahms. El filósofo perseguía el ideal de un diálogo entre 'grandes', de una república de genios y gigantes a través de las épocas y las edades, comenzando por aquellos que eran coetáneos y que posibilitaba que no se estuviera tan solo y aislado en la lucha por una verdadera cultura. Por ello, es obvio que el orgulloso gesto de Wagner le tuvo que parecer «humano, demasiado humano», al margen de la posible y, si se quiere, comprensible y hasta muy legítima justificación estética de su airada y autodefensiva reacción 8 .

La doble audición de la obra de Brahms y el desencuentro con Wagner vinieron a coincidir con la crítica que Karl Hillebrand le hizo a la tercera Consideración Intempestiva por sus inconsiderados ataques antihegelianos, lo cual aumentó sus estéticos «remordimientos de conciencia», al menos en opinión de C. P. Janz ${ }^{9}$. En efecto, en los fragmentos póstumos de 1874, en notas y apuntes que en su parte positiva sirvieron para la redacción de la Cuarta Intempestiva, ya se lee,

8 Para todo este episodio hemos tenido muy en cuenta la versión que narra C. P. Janz en su citada gran biografía Friedrich Nietzsche, 2. Los diez años de Basilea 1869/1879, tr. J. Muñoz e I. Reguera, Alianza, Madrid, 1981, 245-251.

9 Cf. ibid. p. 316. 
en contraste con Brahms, alguna muy significativa crítica observación, que ahora pasamos a mostrar.

II. LOS FRAGMENTOS PÓSTUMOS Y LAS ALUSIONES EN EL EPISTOLARIO A LA MÚSICA DE BRAHMS

Se impone constatar una vez más que el interés central lo conserva la persona y la obra de Wagner. En ese contexto - y sólo en el interior de ese contexto de intereses-el arte de Brahms juega su papel y sirve de contrapunto en algunas ocasiones aisladas. Nótese, por otra parte, que si bien se admite la calidad, la oportunidad y la bondad de la música del compositor de Hamburgo, tampoco suelen faltar los detalles críticos, las reservas, los juicios adversativos que se alejan de lo que nunca es una afirmación positiva, integral e incondicional de su obra. He aquí esta famosa nota de 1874: «La 'falsa omnipotencia' desarrolla algo 'tiránico' en Wagner. El sentimiento de estar sin herederos - por ello intenta darle a su idea de reforma la máxima amplitud y busca reproducirse, por así decirlo, por adopción. Afán de legitimidad». «El tirano no reconoce valor a otras individualidades excepto a la suya y a la de sus personas de confianza. El peligro para Wagner es grande, si no reconoce valor a Brahms, etc. : o a los judíos»10.

Y estos dos apuntes de 1878: «Fenómeno sumamente saludable es Brahms, en cuya música fluye más sangre alemana que en la de Wagner — con lo cual yo quisiera haber dicho muchas cosas buenas, pero en modo alguno sólo cosas buenas»11. «En Wagner, negación ciega de lo bueno (como Brahms), en la facción (la señora Wagner), negación vidente (Lipiner, Rée)»12.

Ya ha comenzado, así pues, la crítica antiwagneriana que estallará en los opúsculos de 1888. En esta evolución se halla presente también Brahms, como han indicado los especialistas: por ejemplo, hablando de Aurora — publicada en 1881 pero redactada en 1880-y del cambio estilístico que en sus páginas se detecta, en cierto modo un tanto 'impresionista', C. P. Janz expone la consiguiente alteración 
que en los juicios sobre gusto ha sufrido Nietzsche, concretamente en los que se refieren a la música: «Ya le resulta imposible no sólo la música de Wagner, sino todo el romanticismo alemán —incluido Brahms. Su estado anímico, su extrema finura de sensibilidad ya no soporta la superabundancia romántica de sentimientos; Nietzsche se siente superado por ella, bien provocado o bien avasallado. En su soledad, esta resuena demasiado fuerte, bien sea sorda o bien estridentemente, por todos los lados. Quiere una música discreta, que, levemente arremangada, baile con un gesto inocente. Para ello acuña la expresión 'música meridional', y la encuentra realizada, en primer lugar, en las composiciones, no precisamente relevantes, de su alemán 'maestro Gast', Heinrich Köselitz»13.

No obstante, cuando el gran biógrafo y musicólogo suizo analiza el Zaratustra y se centra en el año 1883 — el año del estreno de la Tercera sinfonía de Brahms y el año de la composición de la Séptima de Anton Bruckner-, afirma también lo siguiente: «Cuán cercano vivía Nietzsche al espíritu de la música sinfónica alemana de su tiempo, lo muestra el hecho de que califique a su Zaratustra como 'su sinfonía' y coloque con ello - junto al brusco alejamiento de Wagner-su obra al lado de Brahms y de Bruckner»14. ¿Por qué habla de esta nueva cercanía 'sinfónica' a Brahms, lejos de los 'dramas musicales' wagnerianos?

En los apuntes de 1885 reaparece la profunda preocupación por la música de quien escribe «nosotros, los músicos», incluyéndose en el colectivo. Comentando esas notas, C. P. Janz dice que Nietzsche «no sólo dedica a la música como tal algunas consideraciones en sus cuadernos de notas, sino también a músicos como Mendelssohn y Brahms, a quienes, por cierto, infravalora notablemente» 15 . En efecto, a mediados de los años ochenta, a partir de 1885 concretamente, resurgen los breves comentarios sobre éste, siempre al hilo de las incesantes reflexiones, cada vez más críticas, con respecto a Wagner, pero no por ello más condescendientes con otros músicos coetáneos, miembros de ese gran movimiento denominado el Romanticismo.

13 Cf. carta a Köselitz del 17 de noviembre de 1880. C. P. Janz, Friedrich Nietzsche, 3. Los diez años del filósofo errante, p. 52.

14 Cf. op. cit. p. 189.

15 Cf. op. cit. p. 346. 
Brahms no se libra de los golpes, unos por su explícito protestantismo, su supuesto eclecticismo y sus conservadoras dependencias con respecto a la gran tradición de la música clásica, otros a partir del grupo sociológico típicamente 'alemán' de las clases medias que por entonces lo apreciaba porque en él sentía expresada su jerarquía de valores:

«Brahms, ningún 'acontecimiento', ninguna excepción, ninguna ruptura de la cadena anterior a Wagner, más bien un eslabón más, un _- _ - Si de él no se tiene en cuenta lo que en ocasiones ha sacrificado, por así decirlo, a un genio acogedor de estilos y de personas extraños - incluyendo también que ha sido víctima de la piedad para con grandes maestros [Lehrer], antiguos y modernos —es el único músico que hasta ahora tiene derecho a que se le llame "el músico del norte de Alemania" " 16.

«Del mismo modo en que hoy la sumisa medianía en Alemania se siente bien con la música de Brahms, se siente claramente afín a ella-: de ese mismo modo los finos e inseguros galgos del espíritu de París hoy husmean en torno a Renan con una alegre adulación-» 17 .

«Como si después de muchos años al fin por una vez alguien me hablase de los problemas que me preocupan, no, evidentemente, con las respuestas que ya tengo preparadas para resolverlos, sino con las cristianas — que últimamente ha sido la respuesta de las almas más fuertes que han producido nuestros últimos dos siglos. Al escuchar esta música se deja de lado, en efecto, al protestante como un malentendido: del mismo modo que la música de Wagner en Montecarlo me llevó, si no quiero mentir, a dejar de lado incluso la música muy buena que he escuchado (Haydn, Berlioz, Brahms, la obertura de Sigurd de Reyer), como un malentendido de la música. ¡Extraordinario! Cuando era un muchacho me había imaginado con la misión de llevar el misterio al escenario; ———

«-las formas que se toman en préstamo, por ejemplo Brahms, como 'epígono' típico del protestantismo igualmente instruido de Mendelssohn (se imita poéticamente un alma más antigua...)

16 Junio-Julio de 1885.36 [52], KSA 11,571-572.

17 Otoño de 1885-Primavera de 1886. 1 [158], KSA 12, 46.

18 Verano de 1886 - otoño de 1887.5 [41], KSA 12, 199. Esta nota pertenece a los apuntes para La genealogía de la moral, y es la parte final de un fragmento entrecortado, dedicado a exponer la extraordinaria impresión que le produjo al filósofo la audición del "Preludio" de Parsifal. 
las substituciones morales y poéticas en Wagner que constituyen un arte como paliativo de sus carencias en todo lo demás.

El 'sentido histórico', la inspiración a través del poetizar, del decir, esa transformación típica de la cual el ejemplo más claro entre franceses es $\mathrm{G}$. Flaubert, entre alemanes, $R$. Wagner como la fe romántica en el amor y el futuro se cambia en un anhelar la nada, de 1830 a $1850 » 19$.

Así pues, aunque en estas notas se reconoce la gran calidad de la música de Brahms, en último análisis predomina el juicio crítico y negativo sobre el compositor, asociado a lo alemán, nórdico, protestante, romántico, tradicional y mediocre. Es obvio, por lo tanto, que a los ojos de Nietzsche su obra no constituya una sólida alternativa a Wagner. La explosiva crítica de 1888 se estaba fraguando, así pues, en estos papeles íntimos. La futura y fecunda oposición entre música del norte y música del sur, música del Mar del Norte y música del Mediterráneo, empieza a mostrar su primer perfil: la referencia geográfica adquiere pronto caracteres simbólicos de gran relevancia, que en seguida comprobaremos.

El estudio de las aisladas referencias a Brahms que hallamos en algunas cartas confirma esta lectura de sus personalísimas opiniones de los años ochenta. He aquí las pruebas: al comentarle a Köselitz las extraordinarias y fecundas reacciones que le proporciona la audición de la ópera Carmen de Bizet, y criticando por contraste la música del compositor August Bungert (1845-1915), dice Nietzsche que desearía al menos que pudiera aportarle algo de aquella música a éste «y a su schumanniano-brahmsiano idealismo-planeante $\{0$ «idealismo-pendiente-de-un-hilo", zu seinem Schumann-Brabmschen Schebe-Idealismus], que a la larga no soporto: le faltan los huesos» ${ }^{20}$. Reténgase esa asociación con una especie de insoportable caldo o papilla, blanda e in-

19 Finales de 1886 — Primavera de 1887. 7 [7], KSA 12, 285. Esta nota pertenece a un importante fragmento dedicado a exponer la Fisiología del arte, y en el momento de su redacción Nietzsche pensaba que esas ideas formarían el capítulo segundo del libro tercero de su proyectada obra capital. La referencia a Brahms se halla inmediatamente después de un apunte crítico sobre Wagner en el que se cuestiona desde presupuestos fisiológicos que la música de éste sepa caminar y danzar. El contexto de ese apunte es una crítica a toda la música romántica (Beethoven incluido) por su falta de felicidad y de salud, por ser incapaz de divinizar la vida animal, de facilitar la digestión, de aligerar la vida con armonías doradas, para lo cual a Nietzsche le bastan, dice, unos pocos compases.

20 Carta a H. Köselitz del 22 de marzo de 1883, KSB 6, 347. 
consistente, en la que no se puede 'morder' porque carece de huesos y de carne. O con un edificio en equilibrio inestable, frágil y sin sólidos y sanos fundamentos. Preocupado por la suerte de su amigo, el compositor H. Köselitz, Nietzsche usa en otra carta una metáfora similar y le explica a F. Overbeck lo siguiente: «El enemigo que le manifiesta su hostilidad es más bien el oscurantismo y sentimentalismo alemán, consciente $o$ inconsciente, en la segunda ración de sopa caliente, tal como la sirve, por ejemplo Brahms, y, en suma, en la mediocridad alemana del espíritu burgués, que, frente a todo lo meridional, se comporta de una manera recelosamente susceptible y presiente 'frivolidad'. Es la misma antítesis que mi filosofía viene a detectar - en mí y en la música de Köselitz se odia el cielo claro». «Un italiano decía hace poco que "frente a lo que nosotros llamamos celo, el cielo alemán es una caricaturd" [las expresiones subrayadas están en italiano en el original]. ¡Bravo! ¡Aquí está toda mi filosofía!»21.

Estos juicios merecen detallado comentario: la música de Brahms está asociada en ellos al idealismo (¿kantiano? ¿hegeliano?), a la ausencia de buesos (¿inconsistencia del elemento meramente líquido? ¿falta de estructura ósea, de esqueleto o armazón? ¿claroscuro, difuminación, brumas y nieblas nórdicas?), a las constantes nubes grises del clima alemán del Norte, tan diferentes del alegre cielo azul, tan luminoso y claro de los países mediterráneos del Sur de Europa, al oscurantismo (crédulo) y el sentimentalismo (romántico, cristiano y femenino), a la mediocre burguesía que oscila entre la aristocracia a la que no alcanza y los estamentos de trabajadores, disconformes con su esclavitud, a lo alemán, concepto ambiguo, cuestionado e indefinido que, como se sabe, el maduro Nietzsche no dejará de explicar una y otra vez en aguda contraposición con Wagner y el deplorable nacionalismo antisemita de tantos wagnerianos y wagnerianas... Se requeriría un estudio pormenorizado de cada uno de estos términos, frecuentes en los escritos de la madurez del filósofo, que descubriese sus reglas de uso y sus insospechados y precisos significados, pues sólo entonces perderían su abstracta generalidad y mostrarían las aristas de su perfil y la carga crítica que contienen en el seno de una estrategia filosófica que se concreta en tales apreciaciones estéticas: la relectura de los escritos poste- 
riores al Zaratustray, en especial, la de los opúsculos antiwagnerianos lo posibilita con creces. En este contexto de meditaciones filosóficas sobre la suerte de la música y de los diferentes músicos, el solitario e infravalorado Nietzsche vivió una grata sorpresa al leer determinada reseña de uno de sus libros. Las cosas parecían alterarse, como si su juicio estético sufriese un aparente y drástico cambio de rumbo en favor de Brahms.

III. LA RELACIÓN CON JOSEPH VIKTOR WIDMANN Y EL BREVE ACERCAMIENTO A JOHANNES BRAHMS

En el suplemento literario del periódico demócrata-liberal y librepensador Der Bund, el más importante de Basilea, el 16-17 de septiembre de 1886 ( $\mathrm{n}^{\circ} 256$ y n ${ }^{\circ} 257$ ) apareció una recensión de Más allá del bien y del mal firmada por J. V. Widmann que supuso una importante novedad en la vida de Nietzsche: una persona culta captaba la gravedad y el extraordinario peligro de su propuesta filosófica y la comparaba con una carga de dinamita. Ese escritor y crítico cultural era, además, músico y un amigo personal de Brahms, el cual, conocedor de esa reseña y de las opiniones de su inteligente amigo, aceptó sus consejos y comenzó a interesarse por los libros del filósofo.

En 1887, unos meses después, se publican tanto el Hymmus an das Leben (Himno a la vida) para coro mixto y orquesta, la gran composición de Nietzsche con texto de Lou von Salomé, la única que dio a la imprenta y que aprovechaba el núcleo de su Himno a la amistad de 1873/ 74, como La genealogía de la moral. Nietzsche le envía su nuevo libro a J. $\mathrm{V}$. Widmann y parece que con ello se abre la posibilidad de un contacto personal con Brahms - ya que el tratado tercero dedicado al estudio del significado de los ideales ascéticos contiene apartados directamente relacionados con la crítica al artista Wagner, a su persona y a su arte, sobre todo al $P$ arsifal, ataques que los antiwagnerianos se supone que tendrían que leer con sumo agrado. De todo ello hay varios testimonios en el epistolario de Nietzsche.

La primera referencia conjunta a Widmann y a Brahms y a su estrecha colaboración se halla en la carta a H. Köselitz del 8 de junio de 1887 , que contiene una mención al compositor, elogiando la personalidad del director Hans von Bülow y su nobleza en asuntos musicales: "Él [Bülow] se ha enemistado diez veces con Brahms (¿y con quién no?), pero eso no le supone ningún impedimento: al contrario, 
le incita a dedicarse a la fuerza y la originalidad que previamente haya reconocido». Unas líneas después se encuentra este pasaje: «De paso añado que Brahms compone una ópera romántica —está junto al lago de Thun-el texto es de V. Widmann, un arreglo de la comedia de Gozzi El secreto a voces. Al enterarme me he dicho que el citado Dr. Widmann también podría en fin de cuentas escribir el texto de la composición sobre Córcega que usted tiene» 22 .

Al mismo destinatario le comunica lo siguiente en una nueva carta: «Algo curioso de paso: el Dr. Widmann del Bundme ha escrito entusiásticamente; también respecto a $B r a h m s$, con quien está vivamente interesado en Más allá, ahora con idea de llevarse al espíritu la Ciencia jovial. - ¿¿¿¿Podría yo hacer algo en este sentido por Matrimonio segreto [en italiano en el original, título de una composición de Köselitz]??? Interrogación» 23 . Repárese en una doble asociación en la mente de Nietzsche, la que relaciona a Brahms con von Bülow y la que de inmediato establece entre Brahms ( $\mathrm{y}$ Widmann) y la forma de obtener el necesario reconocimiento público de Köselitz como compositor, en un combate ceñido en el que el propio Nietzsche alía explícitamente su filosofía hombro con hombro con la música de su amigo y amanuense, como si ambas fuesen creaciones perfectamente equiparables, carentes todavía de aceptación por motivos idénticos: su antigermanismo, su originalidad y su 'meridionalidad'.

Por lo pronto, al filósofo le alegra que un músico ya consagrado y célebre manifieste interés por su obra. Así lo indica, por ejemplo, la carta a su madre del 12 de agosto de 1887: «Me escriben que el famoso compositor Johannes Brahms (ahora en Suiza) se dedica mucho a mis libros. Parece que tu vieja criatura tiene algo atractivo para los señores músicos» 24 . Al instante, imagina que su propio trabajo como compositor también podría merecer la atención del gran músico, como debemos inferir de la carta a Ernst Wilhelm Fritzsch, el editor de Leipzig que le acababa de publicar su Himno a la vida. «De hecho, no es totalmente improbable que una composición mía pudiera despertar algún

$22 \mathrm{KSB} 8$, 86-87. Este rumor, por entonces bastante extendido, no correspondía en absoluto a la decisión que ya por entonces había tomado el compositor, a saber, prescindir por completo en su vida de futuros proyectos tanto de óperas como de nupcias matrimoniales.

23 Carta a Köselitz del 18 de julio de 1887, KSB 8, 114.

24 KSB 8, 126. 
interés en músicos; me sorprende propiamente lo mucho que precisamente los músicos se dedican incluso a mis escritos - parece que soy para ellos una especie de hombre de confianza. Esto no vale solamente, de ninguna de las maneras, para los músicos wagnerianos; por ejemplo, hace poco me han escrito que el Dr. Joh. Brahms se interesa por mis libros con máxima intensidad [sich auf das Lebhafsteste für meine Bücher interessiret» 25 . Idénticas palabras se encuentran repetidas en la carta a su amigo Franz Overbeck del 30 de agosto ${ }^{26}$. Unos días después estos buenos augurios intentan hacerse realidad. En efecto, en la carta a Josef Viktor Widmann del 11 de septiembre de 1887, en la nota bene, se encuentra esta pregunta: «Por último, ¿estaría usted dispuesto a entregar algo en mi nombre al Sr. Johannes Brahms, en el supuesto de que esté todavía en su cercanía? (a saber, una composición musical mía que aparece justamente ahora: Himno a la vida, para coro y orquesta)... Porque yo soy, en efecto, como decía Wagner, "un músico frustrado" (al igual que él mismo era un "filólogo frustrado"- )»27. Así pues, Nietzsche no sólo consiguió que Brahms conociera su labor musical, sino que procuró que también recibiera su más reciente publicación filosófica: la carta al editor Constantin Georg Naumann de Leipzig del 8 de noviembre de 1887 indica que debe remitirle en nombre del autor un ejemplar del nuevo libro (La genealogía de la morah) al «Sr. Dr. Johannes Brahms», quien ocupa el puesto $n^{\circ} 10$ de una lista de 27 personas amigas y estratégicamente seleccionadas 28 .

La sencilla y escueta respuesta de Brahms, en una tarjeta de visita, nos la transcribe el mismo Nietzsche, literalmente, en la carta a $\mathrm{H}$. Köselitz del 20 de diciembre de 1887: «Nadie más ha contestado al envío del Himno (a la vida) excepto Brahms (escribió "Johannes Brahms se permite darle sus más expresivas gracias por su envío: por la distinción, que como tal la siente él, y por los significativos estímulos que él le debe a usted. Con gran respeto, servidor suyo")» 29 . La carta a Franz Overbeck del 3 de febrero de 1888 recuerda ese gesto, tras una

25 KSB 8, 131. Nótese que aparece aquí una variación en el tratamiento, al compositor se le nombra con el honorífico título de Dr.

26 KSB 8, 140.

27 KSB 8, 150.

28 KSB 8, 187.

29 KSB 8, 212. 
emotiva descripción de su dolorosa soledad: «¿No tengo nada mejor que escribir? He recibido hermosos signos de piedad y de profundo reconocimiento de parte de muchos artistas: entre los cuales el Dr. Brahms, H. von Bülow, Dr. Fuchs y Mottl»30.

Excepto un par de menciones indirectas y de poca relevancia (véanse, por ejemplo, las cartas a $\mathrm{H}$. Köselitz del 13 de febrero de 1888 , en la que, interrogando sobre posibles personalidades o festivales musicales a los que éste debiera acudir para que pudiera darse a conocer como compositor, le informa Nietzsche de que lo único que sabe es que habrá «un [festival] en Stuttgart, en la primera mitad de junio, con Brahms, Albert, Joachim»31, y del 21 de marzo de 1888, en donde copia un pasaje de una carta de Seydlitz, quien le cuenta un viaje a Egipto y describe el horrible viento que allí soplaba, «que parecía una sinfonía de Brahms traducida a lo meteorológico: brutal, lleno de arena, seco, inconcebible, destrozador de los nervios, algo así como un scirocco multiplicado por diez»32), el epistolario sólo contiene —en la carta a Georg Brandes del 27 de marzo de 1888, respuesta al envío del libro de éste sobre el romanticismo alemán ( $1^{\mathrm{a}} \mathrm{ed} .1873$, revisión de 1883) —, un comentario de verdadero interés: «Su 'Romanticismo alemán' me ha hecho recapacitar sobre el hecho de que todo ese movimiento sólo ha llegado propiamente a la meta como música (Schumann, Mendelssohn, Weber, Wagner, Brahms): como literatura quedó únicamente en una gran promesa. Los franceses tuvieron más suerte. - Temo que yo sea demasiado músico como para no ser romántico. Sin música la vida me resultaría un error»33. A la luz de esta reflexión, el nuevo opúsculo que por aquellas fechas comenzó a redactar, denominado El caso Wagner, bien puede entenderse, por lo tanto, como su manifiesto antirromántico, como un fuerte panfleto contra el romanticismo alemán en su acabada madurez musical, unificadora de sonido, danza y poesía en esa obra de arte total que son los dramas musicales de Wagner representándose en Bayreuth. Es obvio, además, que, para Nietzsche, Brahms también pertenecía a

\footnotetext{
30 KSB 8, 242.

31 KSB 8, 252.

32 KSB 8, 276.

33 KSB 8, 279-280.
} 
este movimiento y, como él mismo en cuanto músico, tampoco escapaba a sus críticas más personales y radicales (decadencia, cristianismo, idealismo, germanismo, falsedad, nihilismo, etc.). Hasta aquí, pues, los secretos prolegómenos del texto más importante que Nietzsche redactó sobre el músico de Hamburgo, su opinión más elaborada, unas vibrantes páginas que han merecido que se las llame «El caso Brahms».

\section{EL «Segundo Post-SCRIPTUM» De EL CASO WAGNER}

Este virulento juicio inesperado sobre Brahms en todo lo que su nombre simboliza se redactó aprovechando la necesaria reescritura del manuscrito de ese nuevo opúsculo en Sils-Maria, entre finales de julio y el mes de agosto (hasta el día 24) de 1888. El porqué de tan duro ataque tan sólo es, en cierto modo, una incógnita, si únicamente se tiene en cuenta que un año antes había cordialidad en la relación y parecía que se abrían grandes esperanzas, pero tanto el tono como el contenido pierden parte de su agresiva extrañeza si se conocen los apuntes íntimos que acabamos de revisar y se reconstruye todo el contexto. ¿Hubo una amarga decepción personal por el discreto silencio manifestado por el compositor tanto ante su Himno a la vida como ante el deseado estreno de la ópera de Köselitz? ¿Quería deshacerse Nietzsche del posible rumor que le pudiera convertir automáticamente en 'brahmsiano', una vez liberado de sus pasadas ataduras de 'wagneriano' militante y confeso? ¿Hubo otros motivos que le hicieran redactar ese drástico suplemento? En cualquier caso, y como bien explica C. P. Janz, «para Nietzsche no se daba la alternativa 'Wagner o Brahms', sualternativa era: o bien el romanticismo alemán con sus dos cumbres, Wagner $y$ Brahms —o la superación del romanticismo alemán con su fundamentación filosófica en Hegel y Schopenhauer» mediante la guía imprescindible de una filosofía radicalmente distinta, la suya propia. ${ }^{34}$ En ningún momento se debe leer ese fragmento del panfleto, así pues, como un ataque personal, ya que, por una parte, no fue esa nunca la forma que tuvo Nietzsche de entrar en combate, $y$, por la otra, dicha ofensiva ha de verse como el resultado de una determinada decisión filosófica de superación en su concreción estéti-

34 Op. cit., p. 485. 
ca, en sus directas derivaciones sobre el gusto, es decir, como la culminación de un proceso reflexivo que los fragmentos póstumos y el epistolario nos han permitido reconstruir en su lenta gestación antirromántica, agravada ahora por la radicalidad de las manifestaciones antiwagnerianas que la preceden y la acompañan. No se olvide que todavía estamos en un momento en el que su autor piensa que se halla en plena 'recreación' necesaria de la magna y grave tarea que lleva sobre sus hombros, a saber, la escritura de lo que había proyectado en varios libros como su obra capital, llamada La voluntad de poder, convertida luego, en un primer momento, en Transvaloración de todos los valores...

En efecto, la carta a H. Köselitz del 9 de agosto de 1888 nos amplía la información sobre el sentido de este texto, justo en el momento en que Nietzsche lo acababa de redactar y se lo enviaba a su solícito amanuense para que lo copiara y corrigiera: «Muy llenos de sal y pimienta [se refiere a los dos apartados titulados «Postscriptum» $\mathrm{y}$ «Segundo Postscriptum» de El caso Wagner]; en el segundo Postscriptum agarro por los cuernos el problema de forma ampliada (—no tendré fácilmente oportunidad de hablar de estas cosas de nuevo; la forma, una vez escogida, me permite muchas 'libertades'-) Entre otras cosas, un juicio mortal también sobre Brahms [ein Totengericht auch über Brabms 335".

Que Nietzsche era perfectamente consciente de la implacable sentencia condenatoria, o de la cruel 'vivisección' letal, a las que había sometido al músico lo prueba también el hecho de que no le hiciera llegar a Widmann El caso Wagner para no hacerle sufrir, cosa que reconoce en la carta a Carl Spitteler del 10 de noviembre de 1888: «El que no haya enviado el escrito al señor Dr. Widmann tenía su fundamento en el temor de que podría herirlo en sus simpatías por J. Brahms. Pero puesto que de sus palabras me parece poder deducir que él lo esperaba, tendré el gusto de hacerlo llegar inmediatamente a sus manos», cosa que, en efecto, encargó ese mismo día al editor Naumann 36. La subsiguiente reacción por parte de Widmann demuestra que el filósofo no se había equivocado en sus temores: molesto por las

35 KSB 8, 382.

36 KSB 8, 465-466. Como era de esperar, El caso Wagner de inmediato había recibido una virulenta recepción crítica por parte de los wagnerianos, representados por el 'biógrafo 
invectivas tan faltas de tacto contra su amigo, Widmann contraatacó en un artículo de Der Bund de 20-21 de noviembre, en el que arremetía exageradamente contra Nietzsche como pensador y como persona. La polémica continuó posteriormente, tras el derrumbe del filósofo, entre el escritor suizo y su amigo, el compositor y ensayista Heinrich Köselitz.

Nietzsche pensaba que su opúsculo era un logro notable, como le confesó al fiel e inteligente Overbeck en la carta del 13 de noviembre de 1888, escudándose en la forma indirecta: «Entre tanto he recibido verdaderos escritos de homenaje por mi Caso Wagner. Al escrito lo llaman no sólo una obra maestra psicológica de primer rango, en un terreno en el que hasta ahora nadie en absoluto ha tenido ojos - en la psicología de los músicos; a la ilustración sobre el carácter de décadence de nuestra música en absoluto se la denomina un acontecimiento histórico-cultural, algo que nadie hubiera podido hacer excepto yo: las palabras sobre Brahms son lo máximo de sagacidad psicológica» 37 .

He aquí, por lo tanto, en su integridad y sin más preámbulos, ese texto tan contundente y el contexto completo que lo enmarca: «Parece que mi carta está expuesta a un malentendido. Sobre ciertos rostros se insinúan las arrugas de la gratitud; incluso escucho un tímido regocijo. Preferiría, aquí y en muchas cosas, que se me entendiera. - Sin embargo, desde que en las viñas del espíritu alemán causa estragos un nuevo animal, el gusano del Reich, la famosa rbinoxera, ya no se entiende ni una sola de mis palabras. Me lo atestigua la misma Kreuzzeitung, para no hablar del Litterarisches Centralblatt. - He dado a los alemanes los libros más profundos que poseen — razón suficiente para que los alemanes no entiendan ninguna de las palabras que contienen... Si en este escrito le hago la guerra a Wagner - y, de paso, a un determinado 'gusto' alemán-, si tengo duras palabras contra el cretinismo de

oficial' del compositor, Richard Pohl, quien el 25 de octubre de 1888 publicó en el Musikalisches Wochenblatt un demoledor artículo, «El caso Nietzsche. Un problema psicológico», en el que se decía: «También los admiradores de Brahms han de escuchar lo suyo, pero no loa alguna. Aunque con Brahms se despacha con mayor brevedad que con Wagner, en tanto en cuanto aquél es también menos significativo que éste.» C. P. Janz, op. cit., p. 511.

37 KSB 8, 469-470. 
Bayreuth, no quisiera con ello en modo alguno hacerle el juego a cualquier otro músico, sea el que sea. Otros músicos no cuentan frente a Wagner. La situación es absolutamente desastrosa. La decadencia es universal. La enfermedad está arraigada a mucha profundidad. Si se usa el nombre de Wagner para la ruina de la música, como el de Bernini para la ruina de la escultura, él no es, de ningún modo, su causa. Únicamente ha acelerado su tempo — claro que de una manera tan vertiginosa que uno se queda parado con horror ante esta caída casi fulminante, ante este descenso al abismo. Él tenía la ingenuidad de la décadence: en eso residía su superioridad. Creía en ella, no se detuvo ante ninguna lógica de la décadence. Los demás vacilan - eso es lo único que los diferencia. ¡Y ninguna otra cosa más!... Voy a enumerarlo que hay de común entre Wagner y 'los demás': el hundimiento de la fuerza organizadora; el abuso de los recursos tradicionales sin tener la capacidad que lo justifique, sin un objetivo para usarlos; la falsificación al copiar las grandes formas, para las cuales hoy en día nadie es lo bastante fuerte, orgulloso, seguro de sí mismo, ni lo bastante sano; la supervitalidad en lo más mínimo; el afecto a toda costa; el refinamiento como expresión de la vida empobrecida; cada vez más nervios en lugar de carne. - Sólo conozco a un músico que todavía hoy está en condiciones de componer una obertura de una sola pieza: y nadie lo conoce... Los que hoy son famosos no componen, en comparación con Wagner, una música 'mejor', sino tan sólo una música más indecisa, más indiferente: - más indiferente porque, al existir el todo completo, la mitad incompleta está fuera de lugar. Ahora bien, Wagner era un todo completo; pero era la corrupción completa; era la valentía, la voluntad, la convición en la corrupción— iqué importancia puede seguir teniendo un Johannes Brahms!... La fortuna de éste fue un malentendido alemán: se lo tomó como antagonista de Wagner — ¡Se necesitaba un antagonista! - ¡Eso no lleva a componer música necesaria, eso produce ante todo demasiada música! — ¡Cuando no se es rico se debe ser lo bastante orgulloso para la pobreza!... La simpatía que de manera innegable Brahms inspira aquí y allá, prescindiendo por completo de ese interés partidario, de ese malentendido partidista, para mí fue durante largo tiempo un enigma: hasta que, casi por casualidad, acabé por descubrir que él causa efecto sobre un determinado tipo de humanos. Tiene la melancolía de la incapacidad; no crea a partir de la plenitud, está sediento de plenitud. Si descontamos lo que 
él imita, lo que toma prestado de grandes formas estilísticas antiguas o exótico-modernas —él es un maestro de la copia—, entonces la nostalgia queda como lo más propio suyo... Eso lo adivinan los nostálgicos, los insatisfechos de toda especie. Tiene demasiado poca personalidad, es demasiado poco un punto central... Eso lo entienden los 'impersonales', los periféricos, - por eso lo quieren. Es, en particular, el músico de una especie de mujeres insatisfechas. Cincuenta pasos más: y uno tiene a la wagneriana — exactamente igual que a cincuenta pasos más allá de Brahms encuentra a Wagner-, la wagneriana, un tipo más pronunciado, más interesante, sobre todo más gracioso. Brahms es conmovedor mientras sueña en secreto o llora por él mismo -en eso es 'moderno'-; se vuelve frío y deja de interesarnos en cuanto recoge la herencia de los clásicos... Con gusto se llama a Brahms el heredero de Beethoven: es el eufemismo más cauteloso que conozco. Todo lo que hoy en día pretende alcanzar un 'gran estilo' en la música es, en cuanto tal, o falso con respecto a nosotros, o bien falso consigo mismo. Esta alternativa da bastante que pensar: pues en sí misma implica una casuística sobre el valor de los dos casos. "Falso con respecto a nosotros": contra esto protesta el instinto de la mayoría - no quieren que se los engañe-; yo mismo, por descontado, continuaría prefiriendo este tipo al otro ("falso consigo mismo"). Ése es mi gusto. Expresándome de manera más comprensible, para los 'pobres de espíritu': Brahms - o Wagner... Brahms no es un actor. - Es posible subsumir a una buena parte de los otros músicos bajo el concepto de 'Brahms'.- No digo una palabra de los hábiles monos de Wagner, por ejemplo, de Goldmark: con la Reina de Saba se forma parte de la menagerie [colección de animales], — uno ya puede exhibirse.—Lo pequeño es lo único que hoy en día se puede hacer bien, lo único que hoy en día se puede hacer de una manera magistral. Solamente en lo pequeño es posible todavía la probidad. - Pero, en lo esencial, nada puede curar a la música de lo esencial, de la fatalidad de tener que ser expresión de la contradicción fisiológica- de tener que ser moderna. Una enseñanza óptima, una formación sumamente profunda, una familiaridad con lo fundamental, incluso extremando el aislamiento en compañía de los viejos maestros - todo ello sigue siendo sólo paliativo, ilusorio si hablamos con más rigor, porque ya no se tiene en el cuerpo aquello que es su condición necesaria: la raza fuerte de un Händel, o bien la desbordante animalidad de un Rossini. — No todo 
el mundo tiene derecho a cualquier maestro: esto vale para épocas enteras.- En sí no está excluida la posibilidad de que todavía haya en alguna parte de Europa restos de especies más fuertes, de seres humanos típicamente intempestivos: de lo cual aún cabría esperar también para la música una belleza y una perfección tardías. Las excepciones son, en el mejor de los casos, aquello que todavía podremos vivir en nuestra vida. De la regla de que la corrupción es lo que predomina, de que la corrupción es una fatalidad, de esa regla no hay ningún dios que salve a la música» 38 .

Concluiremos nuestra aproximación al estudio de las relaciones Nietzsche-Brahms sugiriendo algunas líneas hermenéuticas que quizá puedan servir para profundizar en la lectura de estas extraordinarias páginas. C. P. Janz ha interpretado esa célebre «melancolía de la incapacidad» (o de la 'impotencia', Melancholie des Unvermögens) que Nietzsche atribuye a Brahms como un signo de algo que ya conocía el filósofo en él mismo desde su juventud, de algo que incluso ya había formulado casi con las mismas palabras, tal y como aparece en la carta a Wagner del 18 de abril de 1873: «Es verdad, cada día me vuelvo más melancólico (melancholischer) cuando pienso lo mucho que me gustaría ayudarlo o serle de utilidad de algún modo y lo totalmente incapaz que soy de ello (wie ganz und gar unfäbig ich dazu bin)»39. Si el filósofo hubiera tenido la oportunidad de releer este juicio sobre Brahms unos cuantos años después, como pudo hacer con la Terceray la Cuarta de sus Consideraciones Intempestivas, probablemente también hubiera reconocido que en este desenfadado pasaje nos había proporcionado un profundo retrato psicológico indirecto de una parte notable de su propia personalidad. Véaselo, pues, como un importante capítulo de su autobiografía íntima en proyección desplazada, como un breve ensayo enmascarado de lo que bien podría ser un aforismo premonitorio del Ecce homo. Por lo demás, y pensamos que esta pregunta no es en absoluto trivial, ¿aportarían las comparaciones musicológicas, como han dicho ciertos expertos, la prueba de afinidades muy profundas en cuanto a composición, armonia y melodía en-

38 KSA 6, 46-49. Este fragmento pertenece a nuestra edición -introducción, cronología, traducción y notas- de los Escritos completos de Nietzsche sobre Wagner, Biblioteca Nueva, Madrid, 2002 (en prensa).

39 Cf. C. P. Janz, F. Nietzsche, 2, p. 213. El texto de la carta está en KSB 4, 145. 
tre varias obras de Brahms - la Canción triunfal, Un Requiem alemán, la Canción del destino- y el Himno a la vida de Nietzsche, himno que algunos en seguida relacionaron con una coral luterana, o una cantata con texto 'profano', deseoso de reintroducir en los misterios dionisíacos?

Eminentes musicólogos, como Evanghelos Moutsopoulos, han percibido en estas páginas 40 una muestra más de la reiterada tendencia nietzscheana a trazar biparticiones y dualidades, bien documentada desde El nacimiento de la tragedia: lo que en la obra de juventud era la contraposición entre lo dionisíaco y lo apolíneo se convertiría en este fragmento del opúsculo de 1888 en el antagonismo bipartidista previamente resuelto entre Wagner y Brahms, esto es, entre lo dinámico y lo estático, el poder y la impotencia, la acción y la nostalgia, el centro y la periferia, la creación y la copia falsificada o la falsificación, la plenitud y la sed de plenitud, la masculinidad y el feminismo, el progreso y la fijación, el heroico superhombre rebelde y el estoico cristiano resignado, etc. En nuestra opinión, esta lectura aparentemente estructural es víctima de un grave malentendido en lo que se refiere a la filosofía de Nietzsche, que también afecta a su filosofía de la música, un 'malentendido partidista' que el texto desea combatir con toda energía: porque ni Wagner es, en fin de cuentas, el héroe dionisíaco imaginado en la juventud, ni lo es Brahms, ya que tanto el uno como el otro manifiestarían graves síntomas de la enfermedad de la decadencia que arruina el destino de la música y de toda la cultura de la modernidad romántica y cristiana. Con la citada contraposición tan antitética como unilateral se supone además que Nietzsche sigue preso de un insuperable 'wagnerismo incondicional' que le obnubila ante las notables innovaciones y el profundo clasicismo arduamente conquistado de Brahms, el gran 'progresista', el 'romántico antirromántico', el genuino discípulo de Bach y Beethoven, un supuesto equivocado que, al margen de las evidentes limitaciones que se detecten en la lectura nietzscheana de la música de este excepcional compositor-documentables por contraste sila comparamos, por ejemplo, conlo que de Brahms han escrito Schönberg, Bloch y Adorno, tres importan-

40 E. Moutsopoulos, «"Der Fall Brahms” in der Musikphilosophie Nietzsches», en G. Pöltner y H. Vetter (eds.), Nietzsche und die Musik, Peter Lang, Frankfurt a. Main, 1997, pp. 81-84 en especial. 
tes testimonios bien conocidos y muy respetables-, no da ninguna razón del sostenido combate antiwagneriano que ya latía en los años de juventud y que fue ganando argumentos hasta provocar la irrupción de las graves acusaciones de los dos opúsculos de 1888, el verdadero contexto del que procede este 'juicio mortal' sobre el compositor afincado en Viena.

Según Nietzsche, en Wagner también se encuentra el declive de la fuerza organizadora, el abuso de los recursos tradicionales, la falsificación al copiar las formas grandes, la atención a lo mínimo, el predominio de lo afectivo, el refinamiento... Estas características las comparte con Brahms. ¿En qué reside entonces la peculiaridad del músico de Hamburgo? En su nostalgia, en su insatisfacción, en sus sueños secretos y sus llantos, esto es, en su común pertenencia a la modernidad, no en su singular maestría al recoger la herencia de los clásicos. Dada la incapacidad epocal para crear un gran estilo, se dan de hecho dos alternativas al pretenderlo: ser falso con respecto a nosotros, los oyentes, reiterándonos el juego de los grandes músicos - Bach, Händel, Beethoven—, que es lo que hace Brahms, o bien ser falso consigo mismo, que es la opción que practica Wagner, la que ejecuta quien es un actor, un comediante, un simulador... Quizá surja una tercera vía, una excepción intempestiva, capaz de crear una música bella y tardía... Este es, en resumen, el esquema del texto: si, por una parte, reconoce la superioridad de Wagner en cuanto a su ingenuidad de decadente y al carácter de totalidad que reviste su obra y su persona, verdadero paradigma ilustrativo de la situación que atraviesa la cultura europea del momento, por la otra le atribuye a Brahms una modalidad creativa que, en el fondo, prefiere: parece más canónico y tradicional, pero es más auténtico y sincero, no cae en el histrionismo, no es falso consigo mismo. De ahí la veracidad de su música que, como podría decir la figura simbólica creada por el pensador-poeta, mana de un profundo hontanar: de la vida que se saja a sí misma en vivo, de la canción de la melancolía, de la nostalgia en la profunda medianoche por ese placer que quiere profunda eternidad 41 .

41 Este artículo no hubiera sido posible sin una doble incitación, la que debo a la generosa sabiduría de Luis Enrique de Santiago, y la que agradezco a la amistad con Julián Marrades, quien hace décadas consiguió transmitirme su pasión por la música de cámara de Brahms. Desearía que la dedicatoria de este artículo les manifestara mi mejor reconocimiento. 


\section{BIBLIOGRAFÍA ESPECÍFICA}

BERTRAM, E., «Arion», en Nietzsche. Versuch einer Mythologie, G. Bondi, Berlín, 61922, pp. 102-124.

DE SANTIAGO GUERVÓS, L. E., «Nietzsche y los ideales estéticos del sur. La necesidad de mediterraneizar la música», Analecta Malacitana, XXIII 1, 2000, 131-148.

- «F. Nietzsche y la quiebra del ideal artístico wagneriano», en J. B. Llinares (ed), Nietzsche 100 años después, Pre-Textos, Valencia, 2002, en prensa.

GAST, P., «Nietzsche und Brahms», Die Zukunft, 19, 1897, 266-269.

HOLLINRAKE, R., «Wagner and Nietzsche: the Triumplied episode (August 1874)», Nietzsche-Studien, 2, 1973, 196-201.

JANZ, C. P., «Diskussionbeitrag zu David S. Thatcher: Nietzsches Totengericht über Brahms», Nietzsche-Studien, 7, 1978.

MOUTSOPOULOS, E., «'Der Fall Brahms' in der Musikphilosophie Nietzsches», en G. Pöltner y H. Vetter (eds), Nietzsche und die Musik, Peter Lang, Frankfurt a. Main, 1997, pp. 81-91.

REIBER, J., «“Auch das Gegenteil kann wahr sein”. Johannes Brahms, Josef Viktor Widmann und Friedrich Nietzsche», en G. Pöltner y H. Vetter (eds), Nietzsche und die Musik, Peter Lang, Frankfurt a. Main, 1997, pp. 57-79.

ROSS, W., «Ein Jahr in der Schwebe», en Der ängstliche Adler, Deutsche VerlagsAnstalt, Stuttgart, 1980, pp. 386-415.

THATCHER, D. S., «Nietzsche und Brahms. A forgotten Relationship», Musik E letters, 54, 1973, 261-280.

_-, «Nietzsches Totengericht über Brahms», en Nietzsches Verhältnis zu Brahms. WIDMANN, J. V., «Brahms und Nietzsche», Die Zukunft, 19, 1897, 327. , «Nietzsches Abfall von Wagner», Der Bund, 321-322, 20-21 de noviembre de 1888 (Berna). Hay traducción castellana en C. P. Janz, Friedrich Nietzsche 4. Los años de bundimiento 1889/1900, tr. J. Muñoz e I. Reguera, Alianza, Madrid, 1985, pp. 220-228. 